\title{
The motor way: Clinical implications of understanding and shaping actions with the motor system in autism and drug addiction
}

\author{
Luca Casartelli $^{1,2,3} \cdot$ Cristiano Chiamulera $^{4}$
}

Published online: 17 December 2015

(C) Psychonomic Society, Inc. 2015

\begin{abstract}
To understand others' minds is crucial for survival; however, it is quite puzzling how access to others' minds can be - to some extent - direct and not necessarily mediated by conceptual reasoning. Recent advances in neuroscience have led to hypothesize a role for motor circuits not only in controlling the elementary physical features of movement (e.g., force, direction, and amplitude), but also in understanding and shaping human behavior. The concept of "motor cognition" refers to these aspects, and neurophysiological, neuroimaging, and behavioral studies in human and nonhuman primates support this view. From a clinical perspective, motor cognition represents a challenge in several domains. A thorough investigation of the neural mechanisms mediating motor action/intention understanding and automatized/compulsive behaviors seems to be a promising way to tackle a range of neurodevelopmental and drug-related disorders. On the one hand, anomalies in motor cognition may have cascade effects on social functioning in individuals with autism spectrum disorder (ASD); on the other, motor cognition may help explain
\end{abstract}

Luca Casartelli

luca.casartelli@bp.lnf.it

1 IEB - Geneva University Medical School, University of Geneva, Geneva, Switzerland

2 Child Psychopathology Unit, Scientific Institute IRCCS Eugenio MEDEA, Bosisio Parini Lecco, Italy

3 Developmental Psychopathology Unit, Vita-Salute San Raffaele University, Milan, Italy

4 NeuroPsiLab, Department of Diagnostics and Public Health, University of Verona, Verona, Italy the pathophysiology of drug-seeking and drug-taking behaviors in the most severe phase of drug addiction (i.e., see drug dependence, motor low-order cue reactivity). This may represent a promising approach that could improve the efficacy of rehabilitative interventions. The only way to shed light on multifactorial disorders such as ASD and drug addiction is through the investigation of their multiple factors. This motor way can promote new theoretical and experimental perspectives that would help bridge the gap between the basic neuroscience approach and clinical practice.

Keywords Addiction · Social cognition · Drug cue reactivity · Motor cognition · Autism

The ability to thrive in complex social situations is essential for humans. To survive and prosper, it is crucial to understand others' minds, but it is quite puzzling how the access to others can be - to some extent - direct and not necessarily mediated by conceptual reasoning. Recent progress in cognitive and behavioral neuroscience has considerably modified the traditional view of the functional role of the cortical motor system, furnishing a potential answer to such an enigmatic point. Thus, motor areas not only control the elementary physical features of movement (e.g., force, direction, and amplitude), but can also play a role in more complex abilities that contribute to the management of human behaviors (Fig. 1.1). For the sake of simplicity and in accord with recent theoretical models (Casartelli \& Molteni, 2014; Gallese, 2007; Sinigaglia \& Rizzolatti, 2011), we use the term "motor cognition" to refer to the idea that the cortical motor system can play roles in both (i) understanding and (ii) shaping human behavior. Notably, we focus, respectively, on the functional roles of cortical motor areas in social cognition (i.e., motor action/intention 
1.1

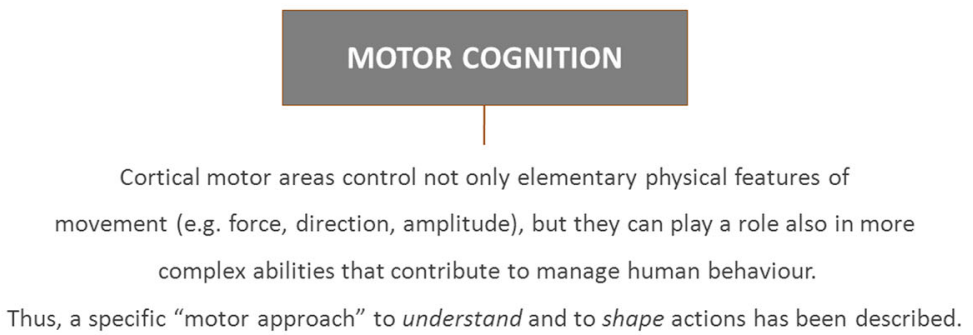

Thus, a specific "motor approach" to understand and to shape actions has been described.

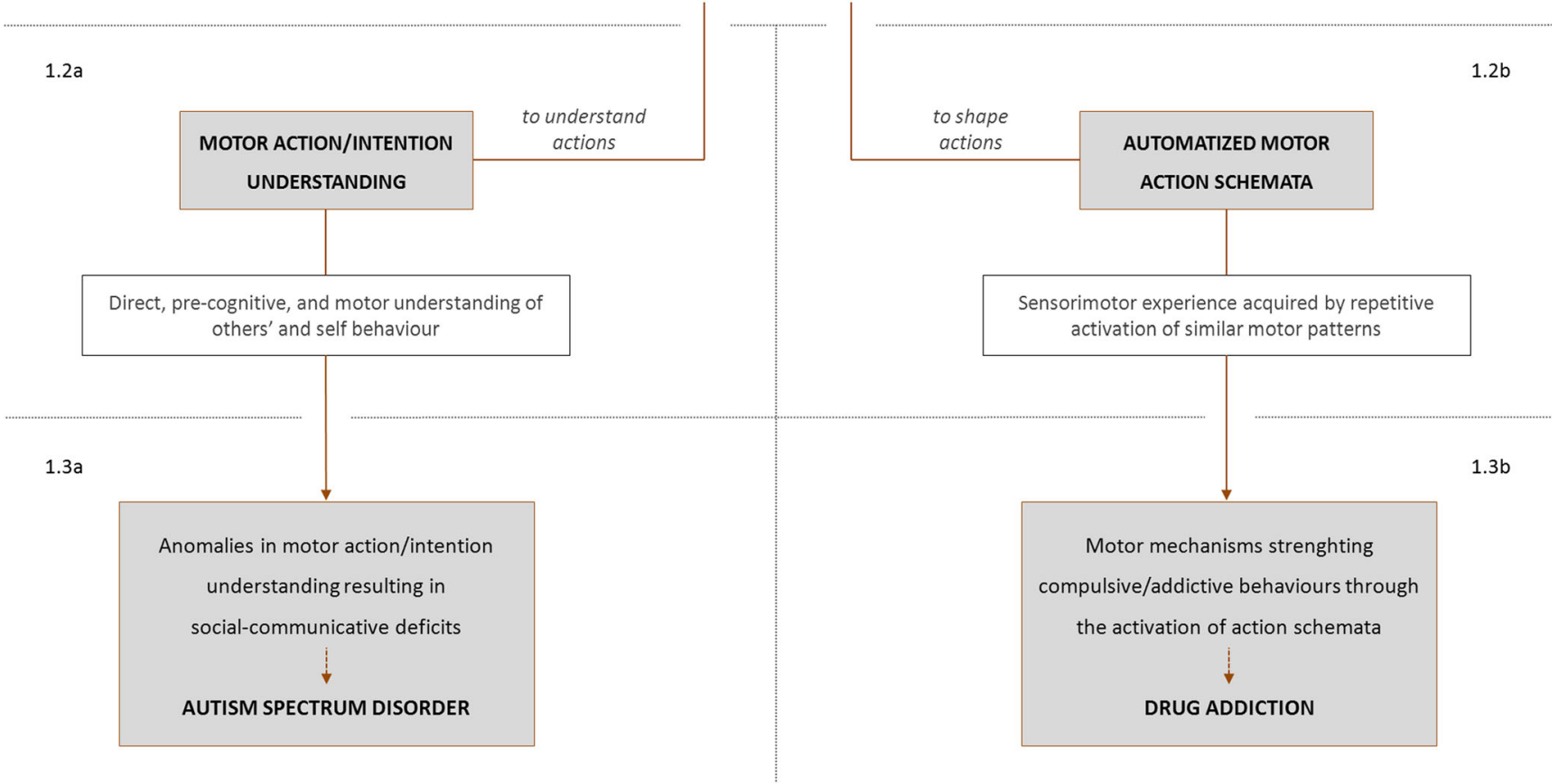

Fig. 1 The term "motor cognition" (1.1) is used when referring to the role of motor areas in understanding (1.2a) and shaping (1.2b) behaviors. The clinical implications for autism spectrum disorder (1.3a) and drug addiction (1.3b) are considered

understanding; Fig. 1.2a) and in the establishment of automatized/compulsive behaviors (Fig. 1.2b).

From a clinical perspective, these different aspects of motor cognition represent a challenge in several domains. A growing number of neurophysiological, neuroimaging, and behavioral studies support the idea that we can have direct, pre-cognitive, and motor understanding of others' behavior. In turn, impairments or anomalies in this motor action/intention understanding may help explain socio-communicative difficulties in individuals with autism spectrum disorder (ASD) (Fig. 1.3a). Interestingly, the functional properties of motor cognition mechanisms may also be relevant for automatized/ compulsive behaviors in the most severe phase of drug addiction. This innovative "motor approach" to drug-seeking and drug-taking behavior may promote new perspectives for therapeutic intervention that can bridge the gap - at least speculatively - between a basic neuroscience approach concerning the motor system and clinical implications in drug addiction (Fig. 1.3b).

In this work, we first present a brief overview of the literature on motor cognition underlying the way in which this "motor" perspective provides innovative insights into understanding and shaping (one's own and others') behaviors. Then, we briefly consider the case of ASD, in which anomalies/impairments of neural mechanisms underlying motor action/intention understanding have been linked to sociocommunicative difficulties. Finally, we focus on drug addiction by considering the potential role of motor cognition mechanisms in shaping automatized/compulsive behaviors in addicts.

\section{Motor cognition: to understand and to shape behaviors in a motor way}

Since pioneering studies on nonhuman primates (Call \& Tomasello, 2008; Premack \&, Woodruff 1978), it has been hypothesized that social interactions in humans are grounded on the ability to attribute propositional attitudes such as beliefs and desires to others. For decades, most authors have considered the notion of theory of mind (ToM) or mindreading the predominant — or even the exclusive — way to access others' 
minds (Baron-Cohen, 1995; Baron-Cohen, Leslie, \& Frith, 1985; Boucher, 2012; Leslie, Friedman, \& German, 2004). However, the putative neural correlates of the so-called "mentalizing system" remain controversial in the literature (Fishman, Keown, Lincoln, Pineda, \& Muller, 2014; Mainieri, Heim, Straube, Binkofski, \& Kircher, 2013; Mitchell, 2008; for a meta-analysis, see Schurz, Radua, Aichhorn, Richlan, \& Perner, 2014). Plausibly, these controversies may be due to the ambiguities of defining in operational terms the notion of ToM, and to the misleading idea that ToM is a unitary process (Bloom \& German, 2000; Schaafsma, Pfaff, Spunt, \& Adolphs, 2015). To overcome the idea that social cognition involves "social metacognition" exclusively (Gallese, 2007), a new approach has been proposed: a multilevel action understanding model that claims that we can understand others' actions through different, non-mutually exclusive, and non-competitive ways (Casartelli \& Molteni, 2014; de Waal \& Ferrari, 2010). Thus, not only metacognitive, inferential, and propositional processes (i.e., high-level social cognition) can support others' understanding, but pre-cognitive, "direct", and "motor" access to others is also possible (i.e., motor social cognition or-more simply_motor cognition; Gallese, 2007; Rizzolatti \& Sinigaglia, 2010) (Fig. 2). Even if it goes beyond the aims of this article, a further and more basic level of social cognition can be drawn - that is, primary social cognition (Jessen \& Grossmann, 2014; Whalen et al., 2004). This level concerns the pre-cognitive and pre-motor understanding of elementary social information that is processed by-for example — visual and auditory perceptual processes or attentional mechanisms (for recent reviews, see Peelle \& Sommers, 2015; Petersen \& Posner, 2012; Vuilleumier, 2015). For example, biological motion processing is an emblematic hallmark of primary social cognition. For our ancestors it was crucial to promptly distinguish between the movement of a living organism (e.g., a potential prey or predator) and a nonbiological movement (e.g., a falling branch). Today, biological motion perception continues to be important for successful daily-life activities, social behavior, and nonverbal communication (Pavlova, 2012). For these reasons, the brain has a highly conserved predisposition to detect biological motion. This is also an early ability ontogenetically speaking, given that preference in recognizing biological motion has been reported in newborns as young as 2 days old (Simion, Regolin, \& Bulf, 2008).

A growing number of studies support the notion that motor cognition is a critical aspect of understanding others. Indeed, the idea that the purposiveness of action can be explained in pre-cognitive, direct, and motor terms has been supported by single-neuron studies in nonhuman primates (Bonini et al., 2010; Fogassi et al., 2005), as well as by neurophysiological (Berchio et al., 2014; Natale et al., 2014), neuroimaging (Buccino et al., 2004; Gazzola \& Keysers, 2009; Iacoboni et al., 2005), and behavioral (Bello et al., 2014; Fabbri-Destro,

\section{MULTI-LEVEL}

\section{ACTION UNDERSTANDING MODEL}

Different, non-competitive and not-mutually exclusive levels of social cognition

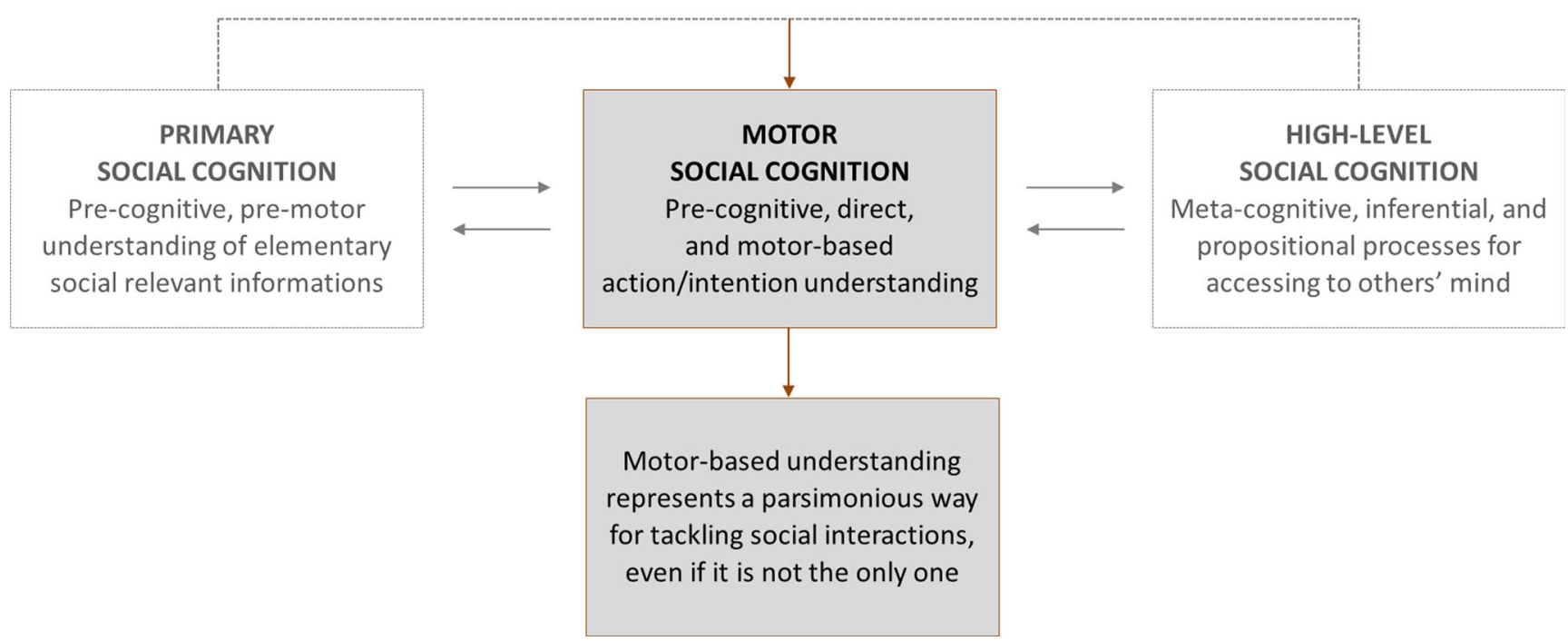

Fig. 2 Different, noncompetitive and non-mutually-exclusive levels of social cognition (the gray boxes and color lines are the parts specifically considered in this study) 
Cattaneo, Boria, \& Rizzolatti, 2009) studies in humans (for theoretical perspectives, see Butterfill \& Sinigaglia, 2014; Sinigaglia, 2013; for reviews, see Ferrari, Bonini, \& Fogassi, 2009; Kilner \& Lemon, 2013; Rizzolatti, Cattaneo, FabbriDestro, \& Rozzi, 2014). Thus, during basic social interactions we do not always need high-level propositional processes to understand others' behaviors: If your friend takes an espresso holding the handle, you directly know that he or she is going to drink it, whereas if he or she takes it grasping the body of the cup, you directly understand that he or she is passing the cup to you. Motor cues (i.e., the type of grasping) are crucial signs that guide our interaction with others, given that they are immediate and pre-cognitive cues. It has been hypothesized that the ability of the motor system to understand others' actions/intentions may be mediated - at least partially-by the parieto-frontal mirror circuit (which includes the inferior parietal lobule, the ventral premotor cortex [vPM], plus the caudal part of the inferior frontal gyrus; for a review, see Rizzolatti et al., 2014). Mirror neurons (MNs) were originally discovered in the ventral premotor cortex (area F5) ( di Pellegrino, Fadiga, Fogassi, Gallese, \& Rizzolatti, 1992; Rizzolatti, Fadiga, Gallese, \& Fogassi, 1996) and later found in the inferior parietal lobule (particularly in area PFG) and the anterior intraparietal area (AIP) of the macaque brain (Fogassi et al., 2005; Rizzolatti \& Sinigaglia, 2010). They represent the neural substrate of a fundamental mechanism able to transform "external" sensory (e.g., visual or auditory) information into the appropriate "internal" motor representation. Singleneuron recording studies in nonhuman primates have indicated that the parieto-frontal MNs discharge when one performs a specific action and when one observes another individual performing the same action (Bonini et al., 2010; Fogassi et al., 2005). A previous study indicated that the majority of grasping MNs in area F5 discharged irrespective of whether grasping was achieved using the right or the left hand, or a precision, whole-hand, or even oral grip (Rochat et al., 2010; Umiltà et al., 2008). Using "normal pliers" (i.e., opening and then closing the fingers to grasp) and "reverse pliers" (i.e., closing and then opening the fingers to grasp), Umiltà et al. (2008) showed that MNs discharged according to the motor goal (i.e., the meaning, to grasp), regardless of the type of pliers. Intriguingly, MNs in area F5 also discharge when monkeys hear the corresponding action-related sounds (Kohler et al., 2002). Thus, MNs code the meaning of an action (e.g., to break a peanut) independently from whether this action is performed (e.g., the monkey breaks a peanut), heard (e.g., the monkey hears the breaking peanut noise), or seen (e.g., the monkey observes the experimenter breaking a peanut) (Rizzolatti \& Sinigaglia, 2010). The fact that some neurons in the cortical motor areas are able to encode the abstract meaning (e.g., to grasp) with such a degree of generality has radically modified the traditional view of the motor system as a mere controller/executor of body displacements. It seems that the motor system also relies - to some extentupon a "teleological" and "social-oriented" structure. Two recent studies in macaque monkeys further support this view. When someone refrains from doing a specific action, he or she might be requested to "internally" represent what one is not doing. Bonini, Maranesi, Livi, Fogassi, and Rizzolatti (2014b) found that the neural pattern underlying the representation of unperformed actions partially reflects the one associated with overtly executed or observed actions. More simply, some F5 grasping neurons discharged both when the monkey grasps an object ("action" condition) and when it refrains from doing this ("inaction" condition) ( Bonini et al., 2014b). Furthermore, Caggiano et al. (2012) showed that the visual response of (a part of) F5 MNs is modulated by the value that the monkey associates with the grasped object. These findings clearly indicate that F5 MNs are not "neutral" to context, showing a preference for specific (more rewarding) objects.

Compelling neurophysiological and brain-imaging experiments also provide indirect evidence for the presence of similar motor understanding mechanisms in humans (Berchio et al., 2014; Cattaneo et al., 2007; Cattaneo, Sandrini, \& Schwarzbach, 2010; Gazzola et al., 2007; Iacoboni et al., 2005; McGarry, Russo, Schalles, \& Pineda, 2012; Ortigue, Sinigaglia, Rizzolatti, \& Grafton, 2010; Peeters et al., 2009; Senna, Bolognini, \& Maravita, 2014; Théoret et al., 2005; for a review, see Rizzolatti et al., 2014). Taken together, these data suggest that also in humans the cortical motor system does not exclusively encode the kinematics of actions but also - and more intriguingly - its meaning. From an evolutionary perspective, the importance of these mechanisms for social life is impressive. The ontogeny of motor action/intention understanding, and more generally the ontogeny of motor cognition in humans, is a fascinating but still controversial issue. A number of studies support a predisposition of the motor system toward the processing of socially relevant information, even before birth (Castiello et al., 2010; Zoia et al., 2007). Recently, two different views have been compared: The so-called "genetic account" suggests that heritable genetic factors and predisposition explain the "mirrorness" of MNs; on the other hand, the "associative account" supports the major role of sensorimotor experience (R. Cook, Bird, Catmur, Press, \& Heyes, 2014). Even if these views have sometimes been described as mutually exclusive, a less rigid "epigenetic approach" that considers the sensorimotor learning phenomena to be related to individual characteristics and context seems more convincing (Ferrari, Tramacere, Simpson, \& Iriki, 2013; Kilner \& Lemon, 2013). Thus, the presence of extremely early, or even innate, mechanisms that are able to encode basic forms of others' direct/motor recognition does not exclude the possibility that learning processes based on sensorimotor experiences may occur. 
The hypothesis that sensorimotor learning may assume a crucial role in the motor system's ability to understand (or to resonate to; see the notion of "motor resonance" in Gallese, Gernsbacher, Heyes, Hickok, \& Iacoboni, 2011) others' actions is supported by a number of experimental studies. Our motor skills significantly affect the way in which we perceive others' actions; the observation of others' actions can activate one's own motor representations (i.e., "action observation-action execution" matching) only if the observer shares the actor's motor repertoire. Interestingly, such ability is a gradual acquisition and can be modulated by practice, as has been suggested by studies on professional athletes (Aglioti, Cesari, Romani, \& Urgesi, 2008; Lahav, Saltzman, \& Schlaug, 2007; Tomeo, Cesari, Aglioti, \& Urgesi, 2013). Furthermore, recent studies have shown that when we observe someone else acting on an object and we already have first-person experience of this action, our own motor representation of the observed action leads us to implement a goal-specific eye movement program identical to that of the actor (Ambrosini, Costantini, \& Sinigaglia, 2011; Ambrosini et al., 2013; Falck-Ytter, Gredeback, \& von Hofsten, 2006). Interestingly, the ventral premotor cortex - a region putatively included in the parieto-frontal mirror networkseems to play a crucial role in this ability (Costantini, Ambrosini, Cardellicchio, \& Sinigaglia, 2013). In an elegant experiment, 14- to 16-month-old infants observed action video during EEG recording. Stronger beta- and mudesynchronizations (the mu rhythm is a rhythm belonging to the alpha frequency band considered an electrophysiological marker of the mirror mechanism in humans) were found for observation of crawling compared to walking videos. The size of this effect was strongly related to the infant's own crawling experience. Considering that 14- to 16-month-old infants have well-established first-person experience with crawling but limited experience with walking, such data support the hypothesis presented above, that motor resonance may be modulated by first-person motor experience (van Elk, van Schie, Hunnius, Vesper, \& Bekkering, 2008). A number of behavioral, electrophysiological, and brain-imaging studies converge on this interpretation (Calvo-Merino, Grèzes, Glaser, Passingham, \& Haggard, 2006; Cross, Hamilton, \& Grafton, 2006; Kanakogi \& Itakura, 2011; Turati et al., 2013; for a review, see Hunnius \& Bekkering, 2014).

To underline the role of motor cognition in the direct action/intention understanding does not exclude that other levels (i.e., primary social cognition and high-level social cognition) play roles in social functioning. On the contrary, these levels have to be considered as noncompetitive and nonmutually-exclusive (Fig. 2). Motor-based understanding represents a parsimonious way to tackle social interactions, even though it is not the only one.

\section{Motor cognition in ASD: motor anomalies impacting on social functioning}

A growing body of studies have focused on different levels of social cognition in ASD. This is not surprising, due to the fact that the capability to promptly understand others is a crucial aspect for survival that emerges early in development, and considering difficulties in social interaction as one of the core features of ASD. With an estimated prevalence of about $1 \%$, ASD is a serious concern for families, clinicians, and generally for caregivers (Lai, Lombardo, \& Baron-Cohen, 2014). To date, clinical diagnosis of ASD is based on behavioral symptoms that include restricted and repetitive patterns of conduct, interests, or activities, and difficulties in (verbal and/or nonverbal) communication/interactions (American Psychiatric Association, 2013; hereafter, DSM 5). Recent changes in diagnostic criteria (Halfon \& Kuo, 2013; Maenner et al., 2014) have had a significant impact on both clinical and research practice, encouraging the study of quantitative markers (sometimes defined also as "biomarkers") that may help support standard behavioral diagnosis. In this context, the term "quantitative" indicates the combination of behavioral/psychophysical (Foss-Feig et al., 2010; Ronconi et al., 2013), neurophysiological (Cattaneo et al., 2007; Vlamings, Jonkman, van Daalen, van der Gaag, \& Kemner, 2010), and neuroimaging (Haar, Berman, Behrmann, \& Dinstein, 2014; Lynch et al., 2013) markers that —in the last decade - have considerably improved our knowledge on the pathophysiology of ASD (for reviews from different perspectives, see Ecker, Bookheimer, \& Murphy, 2015; Kujala, Lepistö, \& Näätänen, 2013; Sacrey, Armstrong, Bryson, \& Zwaigenbaum, 2014; Simmons et al., 2009). Among other areas, studies of the motor cognition anomalies/impairments in ASD represent an intriguing challenge for future research. ${ }^{1}$ Thus, in this section we consider which, if any, difficulties in social interactions in ASD may be attributed (at least partially) to motor cognition mechanisms.

A time-honored clinical tradition has reported general difficulties in the motor domain in ASD. These difficulties have been related to gross and fine motor coordination (Crippa, Forti, Perego, \& Molteni, 2013; Mostofsky et al., 2006), motor control (J. L. Cook, Blakemore, \& Press, 2013; Staples \& Reid, 2010), and locomotor practice (Nobile et al., 2011; for a review, see Gowen \& Hamilton, 2013). These difficulties do not directly impact on social abilities. However, as we

\footnotetext{
${ }^{1}$ Although it is clearly distinct from the aims of this work, social functioning in ASD also has to be considered in light of the multilevel model. Thus, to underline the role of motor cognition anomalies in explaining social interaction difficulties in ASD does not exclude that anomalies/ impairments at other levels (i.e., primary social cognition and high-level social cognition) may play a role in ASD social (mal)functioning (Boucher, 2012; Ronconi et al., 2012; Stevenson et al., 2014; Vlamings et al., 2010).
} 
described above, specific motor mechanisms may also play a role in social functioning (i.e., motor cognition). An intriguing challenge in the field of ASD would be represented by addressing the possibility that anomalies in motor cognition mechanisms might help explain social interaction difficulties. A recent body of studies furnishes support to such a hypothesis (for a review, see Gallese, Rochat, \& Berchio, 2013). The putative activity of the MNs mechanism in typically developing (TD) and ASD individuals was tested using transcranial magnetic stimulation (TMS) and subsequent electromyography (EMG) recordings while subjects observed transitive hand gestures (Enticott et al., 2012; Théoret et al., 2005). Regression analyses showed reduced corticospinal excitability during the observation of transitive hand actions in the ASD group (Enticott et al., 2012). Adapting the experimental design adopted by Fogassi et al. (2005) in humans, Cattaneo et al. (2007) tested with EMG the ability to directly (in a motor way) understand action and intentionality in children with ASD. First, this study aimed to verify whether the chained organization of the parietal and premotor cortex observed in monkeys (Bonini et al., 2010; Fogassi et al., 2005) may have an equivalent in humans. In monkeys, a specific motor act (e.g., grasping) is encoded by F5 and by inferior parietal cortices (area PFG) MNs in markedly different ways (i.e., stronger or weaker activation) when this act is part of actions with different goals (e.g., grasping for eating vs. grasping for placing) (Bonini et al., 2010; Fogassi et al., 2005). Since they are MNs, the encodings are identical for both executed and observed actions. Taken together, these data lead to the hypothesis that this mirror mechanism is able to encode the intentionality of an action (i.e., to eat vs. to place) in a motor way. EMG recording in TD children (Cattaneo et al., 2007), and even in 6-month-old infants (Natale et al., 2014; Turati et al., 2013), supports the existence of a similar motor action/ intention understanding mechanism in humans (Rizzolatti \& Sinigaglia, 2010). The epistemological valence of such a mechanism for motor cognition is intriguing and exciting (Casartelli \& Molteni, 2014; Sinigaglia, 2013). In contrast to TD children, ASD children seem unable to encode the meaning of action (i.e., the motor intentionality, to eat vs. to place) in a motor way (Cattaneo et al., 2007). These findings are also supported by behavioral studies focused on motor-planning abilities (Fabbri-Destro et al., 2009; Forti et al., 2011) and motor intention understanding (Boria et al., 2009; Sparaci, Stefanini, D'Elia, Vicari, \& Rizzolatti, 2014). Overall, these studies indicate that ASD children have difficulties encoding the goal of action in a motor way, limiting the children's abilities to directly understand action/intentionality without any cognitive or high-level mediation. This does not mean that children with ASD do not understand action/intentionality tout court, but it looks as if they cannot profitably take advantage of all levels of social cognition (see Fig. 2) with the same efficiency as TD individuals.
Interestingly, the idea that the motor system may play a significant role in explaining ASD social difficulties is also supported by a recent study by Rochat et al. (2013) that made use of the notion of "vitality forms" (Stern, 2005, 2010), adapting it for experimental contexts (see also Di Cesare, Di Dio, Marchi, \& Rizzolatti, 2015; Di Cesare et al., 2014). When one sees an individual grasping a cup, one does not focus exclusively on the type of act (i.e., to grasp) and on its meaning (i.e., to grasp for drinking vs. to grasp for placing). Aside from goal and motor intention, one is also inclined to observe the style of this action (e.g., rude or gentle). Indeed, the style of an action enables one to understand the attitude of the agent - that is, to some extent, the agent's affective/communicative state (e.g., angry or kind). Thus, the notion of vitality forms refers to the specific action dynamics ("motor prosody") that allow observers to infer an agent's state (Casartelli \& Molteni, 2014). The capability to express and understand vitality forms represents a critical social skill that - if impaired - may have cascade effects on social functioning. In their experiment, Rochat et al. (2013) demonstrated that the ASD group made significantly more errors in recognizing the style of action (i.e., its vitality form; the "how task") than the TD group, whereas no statistically significant differences between groups were reported in recognition of the action goal (e.g., to throw a ball vs. to pass a mug; the "what task"). Neuroimaging studies have shown that the dorsocentral sector of the insula is involved in the recognition (Di Cesare et al., 2014), motor planning (imagery), and execution (Di Cesare et al., 2015) of vitality forms. These results are intriguing in light of previous findings on the general functional organization of the insula in both human and nonhuman primates (Jezzini, Caruana, Stoianov, Gallese, \& Rizzolatti, 2012; Kurth, Zilles, Fox, Laird, \& Eickhoff, 2010). Furthermore, the implication of dorsocentral insula in both the execution and recognition of vitality form raises questions about the mirror properties of this region. This hypothesis would be consistent with functional magnetic resonance imaging (fMRI) findings that have reported similar activations in the anterior section of the insula for the expression and recognition of disgust (Wicker et al., 2003). An additional intriguing point concerns the potential existence of an insulocortical circuit responsible for transmitting vitality form to the cortical circuit controlling motor actions, as was hypothesized by Di Cesare et al. (2014) in line with both nonhuman and human studies (Borra et al., 2008; Borra, Gerbella, Rozzi, \& Luppino, 2011; Gerbella, Belmalih, Borra, Rozzi, \& Luppino, 2011; Rizzolatti et al., 2014).

Taken together, these data strongly support the view that anomalies in the neural circuits supporting motor cognition may have cascade effects on social functioning, contributing to the explanation of social-communicative difficulties in ASD. 


\section{Drug use, drug abuse, and drug dependence: a "motor" approach to drug cue reactivity}

A further domain in which the potential role of the cortical motor system has been widely underestimated is the automatized/compulsive behavior in the most severe phases of substance abuse disorders (DSM 5; McLellan, Cacciola, Alterman, Rikoon, \& Carise, 2006). More specifically, the role of motor cognition in shaping automatized/compulsive addictive behaviors has been almost neglected in the last decades. Considering that it contributes to approximately $12 \%$ of deaths worldwide (World Health Organization, 2002, 2012), drug addiction clearly represents an enormous sociomedical burden for caregivers, as well as a critical challenge for researchers. The pathophysiology of this disorder must be thoroughly understood in order to improve the efficacy of clinical interventions.

A classical view in the literature claims that the chronic exposure to substances of abuse (e.g., nicotine, cocaine, heroin, etc.) results in a cluster of physiological, psychological, and behavioral symptoms; the addict seeks the substance despite the evident consumption-related problems, and such conduct is reinforcing both in positive and negative ways (Belin, Mar, Dalley, Robbins, \& Everitt, 2008; Dalley, Everitt, \& Robbins, 2011; for a review, see Everitt \& Robbins, 2013). The idea that drug addiction is merely a willpower-related disorder or a way of managing psychological distress (Müller \& Schumann, 2011; Pickard, 2011) is not only inappropriate from a neurobiological point of view (Ersche et al., 2013; Naqvi, Rudrauf, Damasio, \& Bechara, 2007; Nutt, King, Saulsbury, \& Blakemore, 2007; for a review, see Everitt et al., 2008), but is also dangerously misleading for the treatment of drug addicts (Chiu, Lohrenz, \& Montague, 2008). Recently, a fierce debate on this point has been reported in the literature (Diana, 2011; Levy, 2013). Without minimizing the obvious role of the degree, amount, and duration of drug exposure and the roles of genetics (Crabbe, Phillips, \& Belknap, 2010; Moeller et al., 2013), environmental/developmental factors (Bardo, Neisewander, \& Kelly, 2013; Doremus-Fitwater, Varlinskaya, \& Spear, 2010), and "gene-to-environment" interactions (Cabib, Orsini, Le Moal, \& Piazza, 2000; Caspi \& Moffitt, 2006), most recent frameworks basically suggest that individual vulnerabilities to substances of abuse may also be related to underlying neuro biological factors (George, Koob, \& Vendruscolo, 2014; Piazza \& Deroche-Gamonet, 2013; Volkow, Wang, Fowler, \& Tomasi, 2012; for a critical debate, see also the comments in Psychopharmacology, 231(19), 2014). Although the distinction between nonpathological and pathological drug users based on behavioral symptoms is a matter of debate, anecdotal and scientific reports agree on the idea that drug use does not necessarily result in drug abuse and drug dependence; rather it has been hypothesized that drug use is on a continuum that can lead to drug addiction (Koob et al., 2004). A classical model distinguished between three consecutive but independent phases (i.e., one phase is necessary but not sufficient to progress toward the next one) with increasing severity: (i) "social use" of the substance, (ii) "regulated relapse," and (iii) "compulsive relapse" (Kalivas \& O’Brien, 2008). This model focuses on relapse, but it seems compatible with more recent ones that distinguish between (1) recreational, sporadic drug use (see also drug use); (2) intensified, sustained, escalated drug use (see also drug abuse); and (3) loss of control of drug intake and full addiction (see also drug addiction) (for a concise overview of the debate, see George et al., 2014). The least severe phase concerns an occasional use of the substance somehow compatible with daily duties and activities; during this phase, the drug user retains the ability to plan and evaluate long-term outcomes. The second phase is more severe, even if the person is generally able to make socially appropriate choices (e.g., the individual is able to make the "right" choice between helping her or his son with homework or taking the substance); during this phase, the individual begins to experience the need to consume the substance regardless of the social, contextual, and contingent situation. In the most severe phase, the exposure to various environmental cues or salient stressors may induce the person to ignore the recognized priorities (e.g., helping with homework) in order to seek and take the substance. In the literature, this phase is often described as an automatized, compulsive, and almost "deterministic" state resulting in the impossibility to evaluate alternatives (i.e., pathological drug intake, behavioral "crystallization"; Piazza \& DerocheGamonet, 2013). An alternative (but not diverging) view describes this third and most serious phase as a sort of strong, disabling, pervading, and recurring propensity to "act" for seeking and taking the substance. From a conceptual point of view, this is not a trivial distinction. Thus, an almost "deterministic" model seems to implicate that you do not have any alternative options, whereas the latter description tries to stress that in drug dependence the individual is continuously led to face the choice (i.e., to take or not take the substance), with a gradually impaired decision-making process that leads to the "wrong" choice (i.e., lapse into drug-seeking and drug-taking behavior). This loss of decision-making ability contributes to the high vulnerability to relapse, even after prolonged abstinence (Belin et al., 2008); relapse may be explained both by an increased desire to consume the substance (mediated by sensitized dopaminergic transmission in the accumbens; Evans et al., 2006; Wanat, Willuhn, Clark, \& Phillips, 2009) and by a decreased functionality of the prefrontal cortex, which involves an impaired ability to control behaviors (Goldstein et al., 2004; Goldstein \& Volkow, 2002, 2011). Obviously, these three phases are 
clearly separated only from a theoretical point of view; indeed, the transition to addiction is a gradual and shifting (and reversible) phenomenon involving individual neurobiological and environmental vulnerabilities (Fig. 3).

A well-characterized non-drug factor associated with addiction is drug "cue reactivity" (CR) - that is, an individual, adaptive response to salient information (or cues) presented in the internal or external environment (Chiamulera, 2005; Drummond, 2000; Niaura et al., 1988). Consistent evidence has shown that salient cues are able to trigger a vast and personalized array of physiological, psychological, and behavioral responses similar to those experienced during substance use (Beaver et al., 2011; Hogarth, Dickinson, \& Duka, 2010; Vollstädt-Klein et al., 2011). Drug CR is one of the major factors involved in the relapse into drug-seeking and drug-taking behavior, and therefore it is an important issue for the development of innovative clinical and rehabilitative approaches. In the literature, one of the most debated distinctions in drug CR is the "high-order CR" and "low-order CR" dichotomy (Tiffany, 1990; for a review, see Tiffany \& Wray,
2012). The high-order CR phenomenon is mediated by the ventral striatum (i.e., non-automatic, conscious, sequential, and slow phenomena; David et al., 2005), as opposed to the low-order CR phenomenon, mediated by the dorsal striatum (i.e., automatic, non-conscious, parallel, and fast phenomena; McClernon, Kozink, Lutz, \& Rose, 2009; for reviews, see Barker \& Taylor, 2014; Everitt \& Robbins, 2005; Wilson, Sayette, \& Fiez, 2004). This view hypothesizes that the progression from use to abuse and then dependence may be characterized as the transition from voluntary to habitual and progressively compulsive drug use. From a neurobiological perspective, such a transition would reflect a dynamic shift in the neural loci of control over behavior (i.e., from the ventral to dorsal striatum, in combination with a progressive decrease in prefrontal cortical control; Everitt \& Robbins, 2013; Garavan et al., 2000; Volkow et al., 2006; Vollstädt-Klein et al., 2011). Although the role of motor processes in the neurobiology of addiction has been widely underestimated or even neglected in past decades (Yalachkov, Kaiser, \& Naumer, 2010), more recently it has been hypothesized that motor mechanisms play

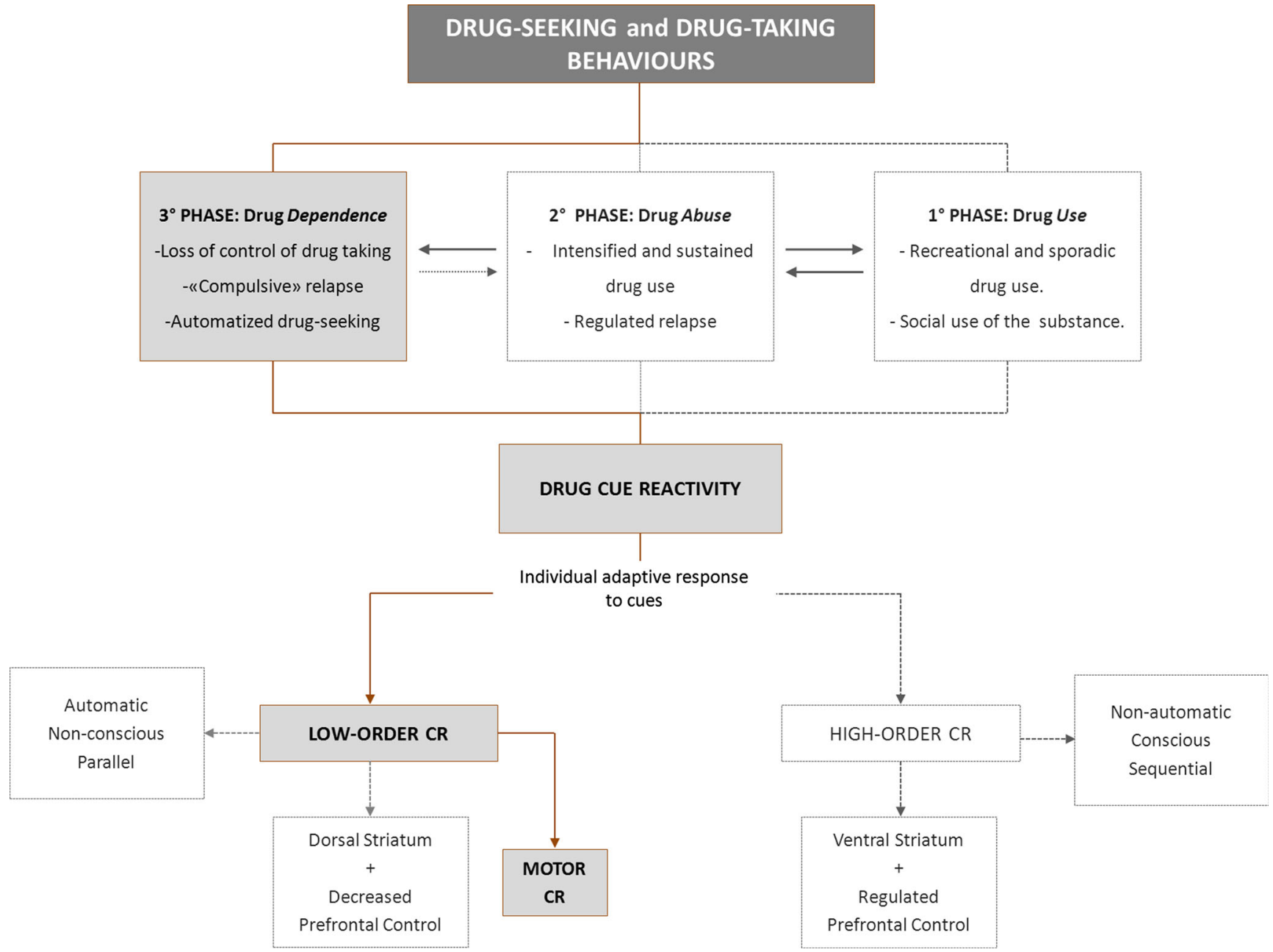

Fig. 3 Drug use, drug abuse, and drug dependence: three consecutive but independent phases with increasing severity. Low-order cue reactivity (CR) plays a potential role in drug-seeking and drug-taking behavior (gray boxes and color lines are the parts specifically considered in this study) 
a role in the low-order CR phenomenon (Brody et al., 2002; Kosten et al., 2006; Smolka et al., 2006; Wagner, Dal Cin, Sargent, Kelley, \& Heatherton, 2011; Yalachkov, Kaiser, \& Naumer, 2009) (see Fig. 3).

To consider addiction as an "all-or-none" condition (i.e., either present or not in a person at a given time) is at odds with most of the current models, which consider addiction as being a continuum (Koob \& Le Moal, 1997; Robinson \& Berridge, 2003). Data on the modulation of motor circuits in low-order CR (i.e., motor low-order CR) further support this nondichotomy view. A positron emission tomography study revealed a strong positive association between the intensity of craving in a heavy smoker group and the relative metabolism in the superior right sensorimotor cortex (including the precentral and postcentral gyrus) (Brody et al., 2002). An fMRI study by Smolka et al. (2006) showed that higher scores of nicotine dependence were associated with a higher fMRI blood-oxygenation-level dependent (BOLD) response to smoking cues in different regions, including premotor cortex, supplementary motor area, and left primary motor cortex. By using an orientation affordance paradigm (i.e., a stimulus-response compatibility paradigm; see Riggio et al., 2008; Tucker \& Ellis, 1998; Vainio, Ellis, \& Tucker, 2007), Yalachkov et al. (2009) found that smokers (but not nonsmokers) showed an automatized responsiveness to smoking paraphernalia similar to that for everyday objects (Yalachkov et al., 2009). Furthermore, from a neural point of view, smokers had higher fMRI activations than nonsmokers not only in regions classically known to be involved in addiction (i.e., left ventral and dorsal striatum, dorsolateral prefrontal cortex, insula, uncus, medial frontal gyrus, right posterior subcallosal gyrus, and bilateral parahippocampal gyrus), but also in a second, "motor" network involving bilateral premotor cortex, left superior parietal lobule, and right lateral cerebellum (Yalachkov et al., 2009; for a review, see Yalachkov, Kaiser, \& Naumer, 2010). These findings seem to suggest that smoking cues in smokers can automatically activate the neural regions encoding the motor representation of "tool use" skills and action meaning (i.e., areas related to motor cognition mechanisms). Intriguingly, in smokers, behavioral performance correlated both with the individual degree of nicotine dependence and with fMRI cue reactivity in some of the regions that encode motor cognition (Yalachkov et al., 2009). This result seems also to be consistent with other studies (McClernon et al., 2009; Park et al., 2007; Smolka et al., 2006). From this perspective, automatized responses to drug-related cues in drug dependence would also be modulated (i.e., strengthened) by direct, pre-reflexive, non-propositional motor responses. In drug users, drug cues may contribute to triggering drug-seeking/drug-taking behaviors by activating brain networks that encode the corresponding drug-related motor repertoire (Jasinska, Stein, Kaiser, Naumer, \& Yalachkov, 2014). In other words, motor cognition mechanisms may play a role in shaping highly compulsive addictive behaviors. ${ }^{2}$

Interestingly, these motor responses are facilitated only when the individual has specific sensorimotor expertise acquired by repetitive activation of similar motor patterns. Smokers are "facilitated" (from both a behavioral and a neural perspective) in using smoking paraphernalia, and this could be a "facilitating factor" for smoking. Put more simply: If you are accustomed to doing it, you will be (from a motor point of view) willing to redo it, and you will be (from a motor point of view) driven to do it again and again. Considering that our brain is able to modulate the neural responses to a specific tool proportionally to the degree of expertise in managing that tool, it is not surprising that - as we outlined above - a nicotine addict responds to smoking paraphernalia as automatically as to everyday objects (Yalachkov et al., 2009). As we previously described, studies on the ontogeny of motor cognition and on professional athletes support this view (Aglioti et al., 2008; Gallese, Rochat, Cossu, \& Sinigaglia, 2009; Lahav et al., 2007; Tomeo et al., 2013). In this sense, a tennis ball for a tennis player may be considered like a smoking-related tool for nicotine addicts. More interestingly, with regard to clinical aims, nicotine addicts' (motor) propensity to activate action schemata related to smoking behavior could - potentiallyfacilitate relapse in nicotine-seeking and/or nicotine-taking behaviors. Thus, this motor mechanism plays a role in shaping (and reinforcing) behaviors (see also Motor cognition: to understand and to shape behaviors in a motor way above). Like professional athletes in their corresponding sport, nicotine addicts may be "facilitated" in returning to and assuming the substance also by motor circuits that - to some extent"know" (and, in turn, facilitate) motor behaviors that have been performed repetitively. Plausibly, a similar mechanism may be observed not only for nicotine but also for different abuse substances, even if further experimental data will be necessary to support this hypothesis. Therefore, motor loworder CR - by increasing the force of that strong disabling, pervading, and recurring propensity to seek and take the substance - would contribute to the characterization of the most severe phase of addiction (i.e., drug dependence; "compulsive relapse", Kalivas \& O’Brien, 2008; "loss of control of drug

\footnotetext{
${ }^{2}$ Drug CR is sometimes associated only with less severe phases of drug addiction (following the previous terminology, drug use and drug abuse), whereas it was presumed that in the most severe phase (drug dependence), the addict does not need cues to experience his or her compulsive need to seek and take the substance (Belin, Jonkman, Dickinson, Robbins, \& Everitt, 2009). Speculatively, we suggest approaching this point by considering that the salience of the cue is also a crucial point in the most severe and compulsive phase. Indeed, the role of salient cues in drug use or drug abuse is undoubtedly because the processing of cues in these phases is - to some extent - conscious. However, by considering the processing of salient cues in the third, compulsive phase as being due to automatic, non-conscious processing (see, "low-order CR" in Fig. 3), we can profitably attribute drug CR also to drug dependence.
} 
intake and full addiction" in Piazza \& Deroche-Gamonet, 2013) (Fig. 3).

An interesting point for further research may concern the modulation of such motor low-order CR; for example, recent works in nonhuman (Caggiano, Fogassi, Rizzolatti, Thier, \& Casile, 2009) and human (Costantini, Ambrosini, Tieri, Sinigaglia, \& Committeri, 2010) primates has shown that our perception of space is not purely metrical, but is also modulated by our ability/potentiality to act in this space (Bonini, Maranesi, Livi, Fogassi, \& Rizzolatti, 2014a; Gallese \& Sinigaglia, 2010, 2011). If our motor system is able to perceive the reachability or nonreachability of an object (i.e., using a spatial alignment effect paradigm, when an object is effectively reachable, we have shorter reaction times; Costantini et al., 2010), then we could speculate that this factor may also modulate motor low-order CR. Future research should also focus on the modulation of CR phenomena by multisensory integration (Yalachkov, Kaiser, Görres, Seehaus, \& Naumer, 2013); an fMRI study has indicated that both nicotine addicts and nonsmokers show visuo-haptic integration in the left lateral occipital complex for common daily objects, whereas only smokers show it during the presentation of smoking paraphernalia (Yalachkov, Kaiser, Görres, Seehaus, \& Naumer, 2012). Taken together, these elements suggest that drug CR is a complex phenomenon that may be significantly modulated by both high-order and low-order mechanisms (Tiffany, 1990). In turn, low-order CR involves not only a dynamic shift in the neural loci of control over behavior (i.e., from the ventral to the dorsal striatum, in combination with a progressive decrease in prefrontal cortical control), but also suggests the possibility that the motor circuits implicated in motor cognition (notably, those involved in shaping behaviors in light of motor expertise) could play a role.

It could be claimed that these studies would not be of relevance for daily clinical practice (for a similar debate, see Maj, 2011). However, a single perspective cannot tackle such a multilayered phenomenon as human behavior, whereas it may be useful to "decompose" (Schaafsma et al., 2015) complexity starting from more basic neurobiological, neurophysiological, and neurocognitive components. Worth noting is that the DSM-5 strategy, driven by recent advances in genetics and neuroscience - in contrast to the descriptive and phenomenological approach of the DSM IV - is consistent with such a view (Regier, Kuhl, \& Kupfer, 2013).

\section{Concluding remarks}

Motor cognition represents an innovative and promising perspective for speculative studies and clinical research (Fig. 1). Clinically, a deeper investigation of the neural mechanisms mediating motor-based action/intention understanding
(Fig. 2) and low-order motor CR (Fig. 3) seems to be a promising way to tackle a range of neurodevelopmental and drugrelated disorders. In ASD, early motor cognition anomalies resulting in basic motor-understanding difficulties could be one of the crucial neurocognitive markers for ASD detection (Becchio, Pierno, Mari, Lusher, \& Castiello, 2007; Cattaneo et al., 2007; Fabbri-Destro et al., 2009; Parma, Bulgheroni, Tirindelli, \& Castiello, 2013; Rochat et al., 2013), and potentially they could be tested even in infancy, before the onset of unequivocal behavioral symptoms (for reviews from nonmotor perspectives, see Jones, Gliga, Bedford, Charman, \& Johnson, 2014; Keehn, Müller, \& Townsend, 2013; Klin, Shultz, \& Jones, 2015). Furthermore, considering that ASD is a lifelong condition that usually requires permanent assistance, motor cognition anomalies may assume a pivotal role for setting (early) rehabilitative protocols to improve social functioning (Pineda, Carrasco, Datko, Pillen, \& Schalles, 2014; Rogers et al., 2014; Zwaigenbaum, Bryson, \& Garon, 2013). Speculatively, the idea that the motor system plays a crucial role not only for controlling the elementary physical features of movement (e.g., force, direction, and amplitude), but also for higher functions (i.e., to understand and to shape behavior; see the introduction), radically changes the way in which we conceive others' behavior and our own (Gallese, 2007; Sinigaglia, 2013; Sinigaglia \& Rizzolatti, 2011). Moreover - even if clinical studies testing (i.e., proving or falsifying) such a hypothesis are necessary-it seems plausible that the plasticity of the cortical motor system may be considered in order to tackle the automatized and compulsive drug-seeking/drug-taking behaviors in substance abuse disorders (Smolka et al., 2006; Wagner et al., 2011; Yalachkov et al., 2009; for a review, see Yalachkov et al., 2010). The transition from use to abuse, and then to addiction, is a critical concept for rehabilitation. Understanding deeply the pathophysiology of this transition may be crucial to addressing drug-taking- and drug-seeking-related problems.

We do not intend to replace the "myth" of "gene talk" (Kendler 2005; Kitcher, 1996) with a new "neuromania" (Legrenzi \& Umiltà, 2011) or a "motor system myth" (Keysers, 2015); we clearly understand the risk of overestimating new neuroscience data, both in clinical and in broader domains (Casartelli \& Chiamulera, 2013a, b). However, the only way to shed light on multifactorial disorders such as ASD and drug addiction will be the investigation of their multiple factors. Potential implications of the motor system in higher functions such as action/intention understanding and automatized/compulsive behaviors cannot be neglected, even if they have to be attentively considered and interpreted in light of the neurobiological complexity of ASD and drug addiction. Obviously, we cannot neglect that the ultimate purpose of these studies should be oriented to clinical practice and, in a broader sense, to the patient's care. The motor way described in this article may be an exemplary 
(speculative, but evidence-based) approach for considering the complexity of neuropsychiatric disorders from different and hopefully useful perspectives. In the future, clinical approaches and therapeutic protocols should attentively consider these findings in order to evaluate their potential clinical impacts in diagnosis and treatment.

Author note L.C. was supported by a grant from the Italian Ministry of Health (2014-2015) and by the Foundation Ernst \& Lucie Schmidheiny (Geneva, Switzerland). We express our gratitude to Flavia Faccio, Marco Pozzi, and Corrado Sinigaglia for their helpful comments.

\section{References}

Aglioti, S. M., Cesari, P., Romani, M., \& Urgesi, C. (2008). Action anticipation and motor resonance in elite basketball players. Nature Neuroscience, 11, 1109-1116.

Ambrosini, E., Costantini, M., \& Sinigaglia, C. (2011). Grasping with the eyes. Journal of Neurophysiology, 106, 1437-1442. doi:10.1152/jn. 00118.2011

Ambrosini, E., Reddy, V., de Looper, A., Costantini, M., Lopez, B., \& Sinigaglia, C. (2013). Looking ahead: Anticipatory gaze and motor ability in infancy. PLOS ONE, 8, e67916. doi:10.1371/journal.pone. 0067916

American Psychiatric Association. (2013). Diagnostic and statistical manual of mental disorders (5th ed.). Washington: Author.

Bardo, M. T., Neisewander, J. L., \& Kelly, T. H. (2013). Individual differences and social influences on the neurobehavioral pharmacology of abused drugs. Pharmacological Reviews, 65, 255-290. doi:10. 1124/pr.111.005124

Barker, J. M., \& Taylor, J. R. (2014). Habitual alcohol seeking: Modeling the transition from casual drinking to addiction. Neuroscience \& Biobehavioral Reviews, 47, 281-294. doi:10.1016/j.neubiorev. 2014.08.012

Baron-Cohen, S. (1995). Mindblindness. Cambridge: MIT Press.

Baron-Cohen, S., Leslie, A. M., \& Frith, U. (1985). Does the autistic child have a "theory of mind"? Cognition, 21, 37-46.

Beaver, J. D., Long, C. J., Cole, D. M., Durcan, M. J., Bannon, L. C., Mishra, R. G., \& Matthews, P. M. (2011). The effects of nicotine replacement on cognitive brain activity during smoking withdrawal studied with simultaneous fMRI/EEG. Neuropsychopharmacology, 36, 1792-1800.

Becchio, C., Pierno, A., Mari, M., Lusher, D., \& Castiello, U. (2007). Motor contagion from gaze: The case of autism. Brain, 130, 24012411. doi:10.1093/brain/awm171

Belin, D., Jonkman, S., Dickinson, A., Robbins, T. W., \& Everitt, B. J. (2009). Parallel and interactive learning processes within the basal ganglia: Relevance for the understanding of addiction. Behavioural Brain Research, 199, 89-102.

Belin, D., Mar, A. C., Dalley, J. W., Robbins, T. W., \& Everitt, B. J. (2008). High impulsivity predicts the switch to compulsive cocaine-taking. Science, 320, 1352-1355. doi:10.1126/science. 1158136

Bello, A., Sparaci, L., Stefanini, S., Boria, S., Volterra, V., \& Rizzolatti, G. (2014). A developmental study on children's capacity to ascribe goals and intentions to others. Developmental Psychology, 50, 504-513. doi:10.1037/a0033375

Berchio, C., Rihs, T. A., Michel, C. M., Brunet, D., Apicella, F., Muratori, F., \& Umiltà, M. A. (2014). Parieto-frontal circuits during observation of hidden and visible motor acts in children. A high-density EEG source imaging study. Brain Topography, 27, 258-270. doi: 10.1007/s10548-013-0314-x
Bloom, P., \& German, T. P. (2000). Two reasons to abandon the false belief task as a test of theory of mind. Cognition, 77, B25-B31.

Bonini, L., Maranesi, M., Livi, A., Fogassi, L., \& Rizzolatti, G. (2014a). Space-dependent representation of objects and other's action in monkey ventral premotor grasping neurons. Journal of Neuroscience, 34, 4108-4119. doi:10.1523/JNEUROSCI.4187-13. 2014

Bonini, L., Maranesi, M., Livi, A., Fogassi, L., \& Rizzolatti, G. (2014b). Ventral premotor neurons encoding representations of action during self and others' inaction. Current Biology, 24, 1611-1614.

Bonini, L., Rozzi, S., Serventi, F. U., Simone, L., Ferrari, P. F., \& Fogassi, L. (2010). Ventral premotor and inferior parietal cortices make distinct contribution to action organization and intention understanding. Cerebral Cortex, 20, 1372-1385. doi:10.1093/cercor/bhp200

Boria, S., Fabbri-Destro, M., Cattaneo, L., Sparaci, L., Sinigaglia, C., Santelli, E., \& Rizzolatti, G. (2009). Intention understanding in autism. PLoS ONE, 4, e5596. doi:10.1371/journal.pone.0005596

Borra, E., Belmalih, A., Calzavara, R., Gerbella, M., Murata, A., Rozzi, S., \& Luppino, G. (2008). Cortical connections of the macaque anterior intraparietal (AIP) area. Cerebral Cortex, 18, 1094-1111. doi:10.1093/cercor/bhm146

Borra, E., Gerbella, M., Rozzi, S., \& Luppino, G. (2011). Anatomical evidence for the involvement of the macaque ventrolateral prefrontal area $12 \mathrm{r}$ in controlling goal-directed actions. Journal of Neuroscience, 31, 12351-12363. doi:10.1523/JNEUROSCI.174511.2011

Boucher, J. (2012). Putting theory of mind in its place: Psychological explanations of the socio-emotional-communicative impairments in autistic spectrum disorder. Autism, 16, 226-246. doi:10.1177/ 1362361311430403

Brody, A. L., Mandelkern, M. A., London, E. D., Childress, A. R., Lee, G. S., Bota, R. G., \& Madsen, D. (2002). Brain metabolic changes during cigarette craving. Archives of General Psychiatry, 59, 11621172 .

Buccino, G., Lui, F., Canessa, N., Patteri, I., Lagravinese, G., Benuzzi, F., \& Rizzolatti, G. (2004). Neural circuits involved in the recognition of actions performed by nonconspecifics: An fMRI study. Journal of Cognitive Neuroscience, 16, 114-126.

Butterfill, S. A., \& Sinigaglia, C. (2014). Intention and motor representation in purposive action. Philosophy and Phenomenological Research, 88, 119-145.

Cabib, S., Orsini, C., Le Moal, M., \& Piazza, P. V. (2000). Abolition and reversal of strain differences in behavioral responses to drugs of abuse after a brief experience. Science, 289, 463-465. doi:10. 1126/science.289.5478.463

Caggiano, V., Fogassi, L., Rizzolatti, G., Casile, A., Giese, M. A., \& Thier, P. (2012). Mirror neurons encode the subjective value of an observed action. Proceedings of the National Academy of Sciences, 109, 11848-11853. doi:10.1073/pnas.1205553109

Caggiano, V., Fogassi, L., Rizzolatti, G., Thier, P., \& Casile, A. (2009). Mirror neurons differentially encode the peripersonal and extrapersonal space of monkeys. Science, 324, 403-406. doi:10. $1126 /$ science. 1166818

Call, J., \& Tomasello, M. (2008). Does the chimpanzee have a theory of mind? 30 years later. Trends in Cognitive Sciences, 12, 187-192. doi:10.1016/j.tics.2008.02.010

Calvo-Merino, B., Grèzes, J., Glaser, D. E., Passingham, R. E., \& Haggard, P. (2006). Seeing or doing? Influence of visual and motor familiarity in action observation. Current Biology, 16, 1905-1910. doi:10.1016/j.cub.2006.07.065

Casartelli, L., \& Chiamulera, C. (2013a). Opportunities, threats and limitations of neuroscience data in forensic psychiatric evaluation. Current Opinion in Psychiatry, 26, 468-473. doi:10.1097/YCO. 0b013e32836342e1 
Casartelli, L., \& Chiamulera, C. (2013b). Which future for neuroscience in forensic psychiatry: Theoretical hurdles and empirical chances. Frontiers in Psychiatry, 4, 74. doi:10.3389/fpsyt.2013.00074

Casartelli, L., \& Molteni, M. (2014). Where there is a goal, there is a way: What, why and how the parieto-frontal mirror network can mediate imitative behaviours. Neuroscience \& Biobehavioral Reviews, 47, 177-193. doi:10.1016/j.neubiorev.2014.08.004

Caspi, A., \& Moffitt, T. E. (2006). Gene-environment interactions in psychiatry: Joining forces with neuroscience. Nature Reviews Neuroscience, 7, 583-590.

Castiello, U., Becchio, C., Zoia, S., Nelini, C., Sartori, L., Blason, L., \& Gallese, V. (2010). Wired to be social: The ontogeny of human interaction. PLoS ONE, 5, e13199. doi:10.1371/journal.pone. 0013199

Cattaneo, L., Fabbri-Destro, M., Boria, S., Pieraccini, C., Monti, A., Cossu, G., \& Rizzolatti, G. (2007). Impairment of actions chains in autism and its possible role in intention understanding. Proceedings of the National Academy of Sciences, 104, 1782517830. doi:10.1073/pnas.0706273104

Cattaneo, L., Sandrini, M., \& Schwarzbach, J. (2010). State-dependent TMS reveals a hierarchical representation of observed acts in the temporal, parietal, and premotor cortices. Cerebral Cortex, 20, 2252-2258. doi:10.1093/cercor/bhp291

Chiamulera, C. (2005). Cue reactivity in nicotine and tobacco dependence: A "multiple-action" model of nicotine as a primary reinforcement and as an enhancer of the effects of smoking-associated stimuli. Brain Research Reviews, 48, 74-97.

Chiu, P. H., Lohrenz, T. M., \& Montague, P. R. (2008). Smokers' brains compute, but ignore, a fictive error signal in a sequential investment task. Nature Neuroscience, 11, 514-520.

Cook, R., Bird, G., Catmur, C., Press, C., \& Heyes, C. (2014). Mirror neurons: From origin to function. Behavioral and Brain Sciences, 37, 177-192. doi:10.1017/S0140525X13000903

Cook, J. L., Blakemore, S. J., \& Press, C. (2013). Atypical basic movement kinematics in autism spectrum conditions. Brain, 136, 28162824. doi:10.1093/brain/awt208

Costantini, M., Ambrosini, E., Cardellicchio, P., \& Sinigaglia, C. (2013). How your hand drives my eyes. Social Cognitive and Affective Neuroscience, 9, 705-711. doi:10.1093/scan/nst037

Costantini, M., Ambrosini, E., Tieri, G., Sinigaglia, C., \& Committeri, G. (2010). Where does an object trigger an action? an investigation about affordances in space. Experimental Brain Research, 207, 95-103. doi:10.1007/s00221-010-2435-8

Crabbe, J. C., Phillips, T. J., \& Belknap, J. K. (2010). The complexity of alcohol drinking: Studies in rodent genetic models. Behavior Genetics, 40, 737-750.

Crippa, A., Forti, S., Perego, P., \& Molteni, M. (2013). Eye-hand coordination in children with high functioning autism and Asperger's disorder using a gap-overlap paradigm. Journal of Autism and Developmental Disorders, 43, 841-850.

Cross, E. S., Hamilton, A. F. D. C., \& Grafton, S. T. (2006). Building a motor simulation de novo: Observation of dance by dancers. NeuroImage, 31, 1257-1267. doi:10.1016/j.neuroimage.2006.01. 033

Dalley, J. W., Everitt, B. J., \& Robbins, T. W. (2011). Impulsivity, compulsivity, and top-down cognitive control. Neuron, 69, 680-694.

David, S. P., Munafò, M. R., Johansen-Berg, H., Smith, S. M., Rogers, R. D., Matthews, P. M., \& Walton, R. T. (2005). Ventral striatum/ nucleus accumbens activation to smoking-related pictorial cues in smokers and nonsmokers: A functional magnetic resonance imaging study. Biological Psychiatry, 58, 488-494.

de Waal, F. B., \& Ferrari, P. F. (2010). Towards a bottom-up perspective on animal and human cognition. Trends in Cognitive Sciences, 14, 201-207.

Di Cesare, G., Di Dio, C., Marchi, M., \& Rizzolatti, G. (2015). Expressing our internal states and understanding those of others.
Proceedings of the National Academy of Sciences, 112, 1033110335. doi:10.1073/pnas.1512133112

Di Cesare, G., Di Dio, C., Rochat, M. J., Sinigaglia, C., BruschweilerStern, N., Stern, D. N., \& Rizzolatti, G. (2014). The neural correlates of "vitality form" recognition: An fMRI study. Social Cognitive and Affective Neuroscience, 9, 951-960. doi:10.1093/scan/nst068

di Pellegrino, G., Fadiga, L., Fogassi, L., Gallese, V., \& Rizzolatti, G. (1992). Understanding motor events: A neurophysiological study. Experimental Brain Research, 91, 176-180.

Diana, M. (2011). The dopamine hypothesis of drug addiction and its potential therapeutic value. Frontiers in Psychiatry, 2, 64. doi:10. 3389/fpsyt.2011.00064

Doremus-Fitzwater, T. L., Varlinskaya, E. I., \& Spear, L. P. (2010). Motivational systems in adolescence: Possible implications for age differences in substance abuse and other risk-taking behaviors. Brain and Cognition, 72, 114-123.

Drummond, D. C. (2000). What does cue-reactivity have to offer clinical research? Addiction, 95, 129-144.

Ecker, C., Bookheimer, S. Y., \& Murphy, D. G. M. (2015). Neuroimaging in autism spectrum disorder: Brain structure and function across the lifespan. Lancet Neurology, 14, 1121-1134. doi:10.1016/S1474442200050-2

Enticott, P. G., Kennedy, H. A., Rinehart, N. J., Tonge, B. J., Bradshaw, J. L., Taffe, J. R., \& Fitzgerald, P. B. (2012). Mirror neuron activity associated with social impairments but not age in autism spectrum disorder. Biological Psychiatry, 71, 427-433.

Ersche, K. D., Jones, P. S., Williams, G. B., Smith, D. G., Bullmore, E. T., \& Robbins, T. W. (2013). Distinctive personality traits and neural correlates associated with stimulant drug use versus familial risk of stimulant dependence. Biological Psychiatry, 74, 137-144.

Evans, A. H., Pavese, N., Lawrence, A. D., Tai, Y. F., Appel, S., Doder, M., \& Piccini, P. (2006). Compulsive drug use linked to sensitized ventral striatal dopamine transmission. Annals of Neurology, 59, 852-858.

Everitt, B. J., Belin, D., Economidou, D., Pelloux, Y., Dalley, J. W., \& Robbins, T. W. (2008). Review. neural mechanisms underlying the vulnerability to develop compulsive drug-seeking habits and addiction. Philosophical Transactions of the Royal Society B, 363, 3125 3135. doi:10.1098/rstb.2008.0089

Everitt, B. J., \& Robbins, T. W. (2005). Neural systems of reinforcement for drug addiction: From actions to habits to compulsion. Nature Neuroscience, 8, 1481-1489.

Everitt, B. J., \& Robbins, T. W. (2013). From the ventral to the dorsal striatum: Devolving views of their roles in drug addiction. Neuroscience \& Biobehavioral Reviews, 37, 1946-1954. doi:10. 1016/j.neubiorev.2013.02.010

Fabbri-Destro, M., Cattaneo, L., Boria, S., \& Rizzolatti, G. (2009). Planning actions in autism. Experimental Brain Research, 192, 521-525. doi:10.1007/s00221-008-1578-3

Falck-Ytter, T., Gredeback, G., \& von Hofsten, C. (2006). Infants predict other people's action goals. Nature Neuroscience, 9, 878-879. doi: $10.1038 / \mathrm{nn} 1729$

Ferrari, P. F., Bonini, L., \& Fogassi, L. (2009). From monkey mirror neurons to primate behaviours: Possible "direct" and "indirect" pathways. Philosophical Transactions of the Royal Society B, 364, 2311-2323. doi:10.1098/rstb.2009.0062

Ferrari, P. F., Tramacere, A., Simpson, E. A., \& Iriki, A. (2013). Mirror neurons through the lens of epigenetics. Trends in Cognitive Sciences, 17, 450-457. doi:10.1016/j.tics.2013.07.003

Fishman, I., Keown, C. L., Lincoln, A. J., Pineda, J. A., \& Muller, R. A. (2014). Atypical cross talk between mentalizing and mirror neuron networks in autism spectrum disorder. JAMA Psychiatry. doi:10. 1001/jamapsychiatry.2014.83

Fogassi, L., Ferrari, P. F., Gesierich, B., Rozzi, S., Chersi, F., \& Rizzolatti, G. (2005). Parietal lobe: From action organization to intention understanding. Science, 308, 662-667. doi:10.1126/science.1106138 
Forti, S., Valli, A., Perego, P., Nobile, M., Crippa, A., \& Molteni, M. (2011). Motor planning and control in autism. A kinematic analysis of preschool children. Research in Autism Spectrum Disorders, 5, 834-842.

Foss-Feig, J. H., Kwakye, L. D., Cascio, C. J., Burnette, C. P., Kadivar, H., Stone, W. L., \& Wallace, M. T. (2010). An extended multisensory temporal binding window in autism spectrum disorders. Experimental Brain Research, 203, 381-389. doi:10.1007/s00221$010-2240-4$

Gallese, V. (2007). Before and below 'theory of mind': Embodied simulation and the neural correlates of social cognition. Philosophical Transactions of the Royal Society B, 362, 659-669. doi:10.1098/ rstb.2006.2002

Gallese, V., Gernsbacher, M. A., Heyes, C., Hickok, G., \& Iacoboni, M. (2011). Perspectives on psychological. Perspectives on Psychological Science, 6, 369-407.

Gallese, V., Rochat, M., Cossu, G., \& Sinigaglia, C. (2009). Motor cognition and its role in the phylogeny and ontogeny of action understanding. Developmental Psychology, 45, 103-113. doi:10.1037/ a0014436

Gallese, V., Rochat, M. J., \& Berchio, C. (2013). The mirror mechanism and its potential role in autism spectrum disorder. Developmental Medicine and Child Neurology, 55, 15-22. doi:10.1111/j.14698749.2012.04398.x

Gallese, V., \& Sinigaglia, C. (2010). The bodily self as power for action. Neuropsychologia, 48, 746-755. doi:10.1016/j.neuropsychologia. 2009.09 .038

Gallese, V., \& Sinigaglia, C. (2011). What is so special about embodied simulation? Trends in Cognitive Sciences, 15, 512-519. doi:10. 1016/j.tics.2011.09.003

Garavan, H., Pankiewicz, J., Bloom, A., Cho, J., Sperry, L., Ross, T. J., \& Stein, E. A. (2000). Cue-induced cocaine craving: Neuroanatomical specificity for drug users and drug stimuli. American Journal of Psychiatry, 157, 1789-1798.

Gazzola, V., \& Keysers, C. (2009). The observation and execution of actions share motor and somatosensory voxels in all tested subjects: Single-subject analyses of unsmoothed fMRI data. Cerebral Cortex, 19, 1239-1255. doi:10.1093/cercor/bhn181

Gazzola, V., van der Worp, H., Mulder, T., Wicker, B., Rizzolatti, G., \& Keysers, C. (2007). Aplasics born without hands mirror the goal of hand actions with their feet. Current Biology, 17, 1235-1240. doi: 10.1016/j.cub.2007.06.045

George, O., Koob, G. F., \& Vendruscolo, L. F. (2014). Negative reinforcement via motivational withdrawal is the driving force behind the transition to addiction. Psychopharmacology, 231, 3911-3917.

Gerbella, M., Belmalih, A., Borra, E., Rozzi, S., \& Luppino, G. (2011). Cortical connections of the anterior (F5a) subdivision of the macaque ventral premotor area F5. Brain Structure and Function, 216, 43-65. doi:10.1007/s00429-010-0293-6

Goldstein, R. Z., Leskovjan, A. C., Hoff, A. L., Hitzemann, R., Bashan, F., Khalsa, S. S., \& Volkow, N. D. (2004). Severity of neuropsychological impairment in cocaine and alcohol addiction: Association with metabolism in the prefrontal cortex. Neuropsychologia, 42, $1447-1458$

Goldstein, R. Z., \& Volkow, N. D. (2002). Drug addiction and its underlying neurobiological basis: Neuroimaging evidence for the involvement of the frontal cortex. American Journal of Psychiatry, 159, $1642-1652$

Goldstein, R. Z., \& Volkow, N. D. (2011). Dysfunction of the prefrontal cortex in addiction: Neuroimaging findings and clinical implications. Nature Reviews Neuroscience, 12, 652-669.

Gowen, E., \& Hamilton, A. (2013). Motor abilities in autism: A review using a computational context. Journal of Autism and Developmental Disorders, 43, 323-344.
Haar, S., Berman, S., Behrmann, M., \& Dinstein, I. (2014). Anatomical abnormalities in autism? Cerebral Cortex. Advance online publication. doi:10.1093/cercor/bhu242

Halfon, N., \& Kuo, A. A. (2013). What DSM-5 could mean to children with autism and their families. JAMA Pediatrics, 167, 608-613. doi: 10.1001/jamapediatrics.2013.2188

Hogarth, L., Dickinson, A., \& Duka, T. (2010). The associative basis of cue-elicited drug taking in humans. Psychopharmacology, 208, 337-351. doi:10.1007/s00213-009-1735-9

Hunnius, S., \& Bekkering, H. (2014). What are you doing? how active and observational experience shape infants' action understanding. Philosophical Transactions of the Royal Society B, 369, 20130490. doi:10.1098/rstb.2013.0490

Iacoboni, M., Molnar-Szakacs, I., Gallese, V., Buccino, G., Mazziotta, J. C., \& Rizzolatti, G. (2005). Grasping the intentions of others with one's own mirror neuron system. PLoS Biology, 3, e79.

Jasinska, A. J., Stein, E. A., Kaiser, J., Naumer, M. J., \& Yalachkov, Y. (2014). Factors modulating neural reactivity to drug cues in addiction: A survey of human neuroimaging studies. Neuroscience \& Biobehavioral Reviews, 38, 1-16. doi:10.1016/j.neubiorev.2013. 10.013

Jessen, S., \& Grossmann, T. (2014). Unconscious discrimination of social cues from eye whites in infants. Proceedings of the National Academy of Sciences, 111, 16208-16213. doi:10.1073/pnas. 1411333111

Jezzini, A., Caruana, F., Stoianov, I., Gallese, V., \& Rizzolatti, G. (2012). Functional organization of the insula and inner perisylvian regions. Proceedings of the National Academy of Sciences, 109, 10077 10082. doi:10.1073/pnas.1200143109

Jones, E. J., Gliga, T., Bedford, R., Charman, T., \& Johnson, M. H. (2014). Developmental pathways to autism: A review of prospective studies of infants at risk. Neuroscience \& Biobehavioral Reviews, 39, 1-33. doi:10.1016/j.neubiorev.2013.12.001

Kalivas, P. W., \& O'Brien, C. (2008). Drug addiction as a pathology of staged neuroplasticity. Neuropsychopharmacology, 33, 166-180. doi:10.1038/sj.npp.1301564

Kanakogi, Y., \& Itakura, S. (2011). Developmental correspondence between action prediction and motor ability in early infancy. Nature Communications, 2, 341.

Keehn, B., Müller, R. A., \& Townsend, J. (2013). Atypical attentional networks and the emergence of autism. Neuroscience \& Biobehavioral Reviews, 37, 164-183. doi:10.1016/j.neubiorev. 2012.11.014

Kendler, K. S. (2005). "A gene for...": The nature of gene action in psychiatric disorders. American Journal of Psychiatry, 162, 12431252. doi:10.1176/appi.ajp.162.7.1243

Keysers, C. (2015). The straw man in the brain. Science, 347, 1259030. doi: $10.1126 /$ science. 1259030

Kilner, J. M., \& Lemon, R. N. (2013). What we know currently about mirror neurons. Current Biology, 23, R1057-R1062. doi:10.1016/j. cub.2013.10.051

Kitcher, P. (1996). The lives to come: The genetic revolution and human possibilities. New York: Simon \& Schuster.

Klin, A., Shultz, S., \& Jones, W. (2015). Social visual engagement in infants and toddlers with autism: Early developmental transitions and a model of pathogenesis. Neuroscience \& Biobehavioral Reviews, 50, 189-203. doi:10.1016/j.neubiorev.2014.10.006

Kohler, E., Keysers, C., Umiltà, M. A., Fogassi, L., Gallese, V., \& Rizzolatti, G. (2002). Hearing sounds, understanding actions: Action representation in mirror neurons. Science, 297, 846-848. doi:10.1126/science.1070311

Koob, G. F., Ahmed, S. H., Boutrel, B., Chen, S. A., Kenny, P. J., Markou, A., \& Sanna, P. P. (2004). Neurobiological mechanisms in the transition from drug use to drug dependence. Neuroscience \& Biobehavioral Reviews, 27, 739-749. 
Koob, G. F., \& Le Moal, M. (1997). Drug abuse: Hedonic homeostatic dysregulation. Science, 278, 52-58.

Kosten, T. R., Scanley, B. E., Tucker, K. A., Oliveto, A., Prince, C., Sinha, R., \& Wexler, B. E. (2006). Cue-induced brain activity changes and relapse in cocaine-dependent patients. Neuropsychopharmacology, 31, 644-650. doi:10.1038/sj.npp. 1300851

Kujala, T., Lepistö, T., \& Näätänen, R. (2013). The neural basis of aberrant speech and audition in autism spectrum disorders. Neuroscience \& Biobehavioral Reviews, 37, 697-704. doi:10.1016/j.neubiorev. 2013.01.006

Kurth, F., Zilles, K., Fox, P. T., Laird, A. R., \& Eickhoff, S. B. (2010). A link between the systems: Functional differentiation and integration within the human insula revealed by meta-analysis. Brain Structure and Function, 214, 519-534.

Lahav, A., Saltzman, E., \& Schlaug, G. (2007). Action representation of sound: Audiomotor recognition network while listening to newly acquired actions. Journal of Neuroscience, 27, 308-314. doi:10. 1523/JNEUROSCI.4822-06.2007

Lai, M. C., Lombardo, M. V., \& Baron-Cohen, S. (2014). Autism. Lancet, 383, 896-910. doi:10.1016/S0140-673661539-1

Legrenzi, P., \& Umiltà, C. (2011). Neuromania: On the limits of brain science. Oxford: Oxford University Press.

Leslie, A. M., Friedman, O., \& German, T. P. (2004). Core mechanisms in 'theory of mind'. Trends in Cognitive Sciences, 8, 528-533.

Levy, N. (2013). Addiction is not a brain disease (and it matters). Frontiers in Psychiatry, 4, 24. doi:10.3389/fpsyt.2013.00024

Lynch, C. J., Uddin, L. Q., Supekar, K., Khouzam, A., Phillips, J., \& Menon, V. (2013). Default mode network in childhood autism: Posteromedial cortex heterogeneity and relationship with social deficits. Biological Psychiatry, 74, 212-219.

Maenner, M. J., Rice, C. E., Arneson, C. L., Cunniff, C., Schieve, L. A., Carpenter, L. A., \& Durkin, M. S. (2014). Potential impact of DSM5 criteria on autism spectrum disorder prevalence estimates. JAMA Psychiatry, 71, 292-300

Mainieri, A. G., Heim, S., Straube, B., Binkofski, F., \& Kircher, T. (2013). Differential role of the Mentalizing and the Mirror Neuron system in the imitation of communicative gestures. NeuroImage, 81, 294-305.

Maj, M. (2011). Is it possible to explain complex mental disorders at the biological level? World Psychiatry, 10, 1.

McClernon, F. J., Kozink, R. V., Lutz, A. M., \& Rose, J. E. (2009). 24-h smoking abstinence potentiates fMRI-BOLD activation to smoking cues in cerebral cortex and dorsal striatum. Psychopharmacology, 204, 25-35.

McGarry, L. M., Russo, F. A., Schalles, M. D., \& Pineda, J. A. (2012). Audio-visual facilitation of the mu rhythm. Experimental Brain Research, 218, 527-538.

McLellan, A. T., Cacciola, J. C., Alterman, A. I., Rikoon, S. H., \& Carise, D. (2006). The Addiction Severity Index at 25: Origins, contributions and transitions. American Journal on Addiction, $15,113-124$

Mitchell, J. P. (2008). Activity in right temporo-parietal junction is not selective for theory-of-mind. Cerebral Cortex, 18, 262-271. doi:10. 1093/cercor/bhm051

Moeller, S. J., Parvaz, M. A., Shumay, E., Beebe-Wang, N., Konova, A. B., Alia-Klein, N., \& Goldstein, R. Z. (2013). Gene x abstinence effects on drug cue reactivity in addiction: Multimodal evidence. Journal of Neuroscience, 33, 10027-10036. doi:10.1523/ JNEUROSCI.0695-13.2013

Mostofsky, S. H., Dubey, P., Jerath, V. K., Jansiewicz, E. M., Goldberg, M. C., \& Denckla, M. B. (2006). Developmental dyspraxia is not limited to imitation in children with autism spectrum disorders. Journal of the International Neuropsychological Society, 12, 314-326.
Müller, C. P., \& Schumann, G. (2011). Drugs as instruments: A new framework for non-addictive psychoactive drug use. Behavioral and Brain Sciences, 34, 293-310.

Naqvi, N. H., Rudrauf, D., Damasio, H., \& Bechara, A. (2007). Damage to the insula disrupts addiction to cigarette smoking. Science, 315, 531-534. doi:10.1126/science.1135926

Natale, E., Senna, I., Bolognini, N., Quadrelli, E., Addabbo, M., Cassia, V. M., \& Turati, C. (2014). Predicting others' intention involves motor resonance: EMG evidence from 6- and 9-month-old infants. Developmental Cognitive Neuroscience, 7, 23-29.

Niaura, R. S., Rohsenow, D. J., Binkoff, J. A., Monti, P. M., Pedraza, M., \& Abrams, D. B. (1988). Relevance of cue reactivity to understanding alcohol and smoking relapse. Journal of Abnormal Psychology, 97, 133-152.

Nobile, M., Perego, P., Piccinini, L., Mani, E., Rossi, A., Bellina, M., \& Molteni, M. (2011). Further evidence of complex motor dysfunction in drug naive children with autism using automatic motion analysis of gait. Autism, 15, 263-283. doi:10.1177/1362361309356929

Nutt, D., King, L. A., Saulsbury, W., \& Blakemore, C. (2007). Development of a rational scale to assess the harm of drugs of potential misuse. Lancet, 369, 1047-1053.

Ortigue, S., Sinigaglia, C., Rizzolatti, G., \& Grafton, S. T. (2010). Understanding actions of others: The electrodynamics of the left and right hemispheres. A high-density EEG neuroimaging study. PLoS ONE, 5, e12160. doi:10.1371/journal.pone.0012160

Park, M.-S., Sohn, J.-H., Suk, J.-A., Kim, S.-H., Sohn, S., \& Sparacio, R. (2007). Brain substrates of craving to alcohol cues in subjects with alcohol use disorder. Alcohol and Alcoholism, 42, 417-422. doi:10. 1093/alcalc/agl117

Parma, V., Bulgheroni, M., Tirindelli, R., \& Castiello, U. (2013). Body odors promote automatic imitation in autism. Biological Psychiatry, 74, 220-226. doi:10.1016/j.biopsych.2013.01.010

Pavlova, M. A. (2012). Biological motion processing as a hallmark of social cognition. Cerebral Cortex, 22, 981-995. doi:10.1093/cercor/ bhr156

Peelle, J. E., \& Sommers, M. S. (2015). Prediction and constraint in audiovisual speech perception. Cortex, 68, 169-181. doi:10.1016/ j.cortex.2015.03.006

Peeters, R., Simone, L., Nelissen, K., Fabbri-Destro, M., Vanduffel, W., Rizzolatti, G., \& Orban, G. A. (2009). The representation of tool use in humans and monkeys: Common and uniquely human features. Journal of Neuroscience, 29, 11523-11539. doi:10.1523/ JNEUROSCI.2040-09.2009

Petersen, S. E., \& Posner, M. I. (2012). The attention system of the human brain: 20 years after. Annual Review of Neuroscience, 35, 73-89. doi:10.1146/annurev-neuro-062111-150525

Piazza, P. V., \& Deroche-Gamonet, V. (2013). A multistep general theory of transition to addiction. Psychopharmacology, 229, 387-413. doi: 10.1007/s00213-013-3224-4

Pickard, H. (2011). The instrumental rationality of addiction. Behavioral and Brain Sciences, 34, 320-321.

Pineda, J. A., Carrasco, K., Datko, M., Pillen, S., \& Schalles, M. (2014). Neurofeedback training produces normalization in behavioural and electrophysiological measures of high-functioning autism. Philosophical Transactions of the Royal Society B, 369, 20130183. doi:10.1098/rstb.2013.0183

Premack, D., \& Woodruff, G. (1978). Does the chimpanzee have a theory of mind? Behavioral and Brain Sciences, 1, 515-526. doi:10.1017/ S0140525X00076512

Regier, D. A., Kuhl, E. A., \& Kupfer, D. J. (2013). The DSM-5: Classification and criteria changes. World Psychiatry, 12, 92-98. doi:10.1002/wps. 20050

Riggio, L., Iani, C., Gherri, E., Benatti, F., Rubichi, S., \& Nicoletti, R. (2008). The role of attention in the occurrence of the affordance effect. Acta Psychologica, 127, 449-458. 
Rizzolatti, G., Cattaneo, L., Fabbri-Destro, M., \& Rozzi, S. (2014). Cortical mechanisms underlying the organization of goal-directed actions and mirror neuron-based action understanding. Physiological Reviews, 94, 655-706. doi:10.1152/physrev.00009. 2013

Rizzolatti, G., Fadiga, L., Gallese, V., \& Fogassi, L. (1996). Premotor cortex and the recognition of motor actions. Cognitive Brain Research, 3, 131-141.

Rizzolatti, G., \& Sinigaglia, C. (2010). The functional role of the parietofrontal mirror circuit: Interpretations and misinterpretations. Nature Reviews Neuroscience, 11, 264-274. doi:10.1038/nrn2805

Robinson, T. E., \& Berridge, K. C. (2003). Addiction. Annual Review of Psychology, 54, 25-53. doi:10.1146/annurev.psych.54.101601. 145237

Rochat, M. J., Caruana, F., Jezzini, A., Escola, L., Intskirveli, I., Grammont, F., \& Umiltà, M. A. (2010). Responses of mirror neurons in area F5 to hand and tool grasping observation. Experimental Brain Research, 204, 605-616. doi:10.1007/s00221-010-2329-9

Rochat, M. J., Veroni, V., Bruschweiler-Stern, N., Pieraccini, C., BonnetBrilhault, F., Barthelemy, C., \& Rizzolatti, G. (2013). Impaired vitality form recognition in autism. Neuropsychologia, 51, 19181924. doi:10.1016/j.neuropsychologia.2013.06.002

Rogers, S., Vismara, L., Wagner, A., McCormick, C., Young, G., \& Ozonoff, S. (2014). Autism treatment in the first year of life: A pilot study of infant start, a parent-implemented intervention for symptomatic infants. Journal of Autism and Developmental Disorders, 44, 2981-2995.

Ronconi, L., Gori, S., Giora, E., Ruffino, M., Molteni, M., \& Facoetti, A. (2013). Deeper attentional masking by lateral objects in children with autism. Brain and Cognition, 82, 213-218. doi:10.1016/j. bandc.2013.04.006

Ronconi, L., Gori, S., Ruffino, M., Franceschini, S., Urbani, B., Molteni, M., \& Facoetti, A. (2012). Decreased coherent motion discrimination in autism spectrum disorder: The role of attentional zoom-out deficit. PLoS ONE, 7, e49019. doi:10.1371/journal.pone.0049019

Sacrey, L.-A., Armstrong, V. L., Bryson, S. E., \& Zwaigenbaum, L. (2014). Impairments to visual disengagement in autism spectrum disorder: A review of experimental studies from infancy to adulthood. Neuroscience \& Biobehavioral Reviews, 47, 559-577. doi:10. 1016/j.neubiorev.2014.10.011

Schaafsma, S. M., Pfaff, D. W., Spunt, R. P., \& Adolphs, R. (2015). Deconstructing and reconstructing theory of mind. Trends in Cognitive Sciences, 19, 65-72. doi:10.1016/j.tics.2014.11.007

Schurz, M., Radua, J., Aichhorn, M., Richlan, F., \& Perner, J. (2014). Fractionating theory of mind: A meta-analysis of functional brain imaging studies. Neuroscience \& Biobehavioral Reviews, 42, 9-34.

Senna, I., Bolognini, N., \& Maravita, A. (2014). Grasping with the foot: Goal and motor expertise in action observation. Human Brain Mapping, 35, 1750-1760.

Simion, F., Regolin, L., \& Bulf, H. (2008). A predisposition for biological motion in the newborn baby. Proceedings of the National Academy of Sciences, 105, 809-813. doi:10.1073/pnas.0707021105

Simmons, D. R., Robertson, A. E., McKay, L. S., Toal, E., McAleer, P., \& Pollick, F. E. (2009). Vision in autism spectrum disorders. Vision Research, 49, 2705-2739.

Sinigaglia, C. (2013). What type of action understanding is subserved by mirror neurons? Neuroscience Letters, 540, 59-61.

Sinigaglia, C., \& Rizzolatti, G. (2011). Through the looking glass: Self and others. Consciousness and Cognition, 20, 64-74. doi:10.1016/j. concog.2010.11.012

Smolka, M. N., Bühler, M., Klein, S., Zimmermann, U., Mann, K., Heinz, A., \& Braus, D. F. (2006). Severity of nicotine dependence modulates cue-induced brain activity in regions involved in motor preparation and imagery. Psychopharmacology, 184, 577-588.

Sparaci, L., Stefanini, S., D’Elia, L., Vicari, S., \& Rizzolatti, G. (2014). What and why understanding in autism spectrum disorders and
Williams syndrome: Similarities and differences. Autism Research, 7, 421-432. doi:10.1002/aur.1370

Staples, K. L., \& Reid, G. (2010). Fundamental movement skills and autism spectrum disorders. Journal of Autism and Developmental Disorders, 40, 209-217. doi:10.1007/s10803-009-0854-9

Stern, D. (2005). The present moment in psychotherapy and everyday life. New York: Norton.

Stern, D. (2010). Forms of vitality: Exploring dynamic experience in psychology, the arts, psychotherapy, and development. Oxford: Oxford University Press.

Stevenson, R. A., Siemann, J. K., Schneider, B. C., Eberly, H. E., Woynaroski, T. G., Camarata, S. M., \& Wallace, M. T. (2014). Multisensory temporal integration in autism spectrum disorders. Journal of Neuroscience, 34, 691-697. doi:10.1523/JNEUROSCI. 3615-13.2014

Théoret, H., Halligan, E., Kobayashi, M., Fregni, F., Tager-Flusberg, H., $\&$ Pascual-Leone, A. (2005). Impaired motor facilitation during action observation in individuals with autism spectrum disorder. Current Biology, 15, R84-R85.

Tiffany, S. T. (1990). A cognitive model of drug urges and drug-use behavior: Role of automatic and nonautomatic processes. Psychological Review, 97, 147.

Tiffany, S. T., \& Wray, J. M. (2012). The clinical significance of drug craving. Annals of the New York Academy of Sciences, 1248, 1-17. doi:10.1111/j.1749-6632.2011.06298.x

Tomeo, E., Cesari, P., Aglioti, S. M., \& Urgesi, C. (2013). Fooling the kickers but not the goalkeepers: Behavioral and neurophysiological correlates of fake action detection in soccer. Cerebral Cortex, 23, 2765-2778. doi:10.1093/cercor/bhs279

Tucker, M., \& Ellis, R. (1998). On the relations between seen objects and components of potential actions. Journal of Experimental Psychology: Human Perception and Performance, 24, 830-846. doi:10.1037/0096-1523.24.3.830

Turati, C., Natale, E., Bolognini, N., Senna, I., Picozzi, M., Longhi, E., \& Cassia, V. M. (2013). The early development of human mirror mechanisms: Evidence from electromyographic recordings at 3 and 6 months. Developmental Science, 16, 793-800. doi:10.1111/desc. 12066

Umiltà, M. A., Escola, L., Intskirveli, I., Grammont, F., Rochat, M., Caruana, F., ... Rizzolatti, G. (2008). When pliers become fingers in the monkey motor system. Proceedings of the National Academy of Sciences, 105, 2209-2213. doi:10.1073/pnas.0705985105

Vainio, L., Ellis, R., \& Tucker, M. (2007). The role of visual attention in action priming. Quarterly Journal of Experimental Psychology, 60, 241-261.

van Elk, M., van Schie, H. T., Hunnius, S., Vesper, C., \& Bekkering, H. (2008). You'll never crawl alone: Neurophysiological evidence for experience-dependent motor resonance in infancy. NeuroImage, 43, 808-814.

Vlamings, P. H. J. M., Jonkman, L. M., van Daalen, E., van der Gaag, R. J., \& Kemner, C. (2010). Basic abnormalities in visual processing affect face processing at an early age in autism spectrum disorder. Biological Psychiatry, 68, 1107-1113. doi:10.1016/j.biopsych. 2010.06.024

Volkow, N. D., Wang, G.-J., Fowler, J. S., \& Tomasi, D. (2012). Addiction circuitry in the human brain. Annual Review of Pharmacology and Toxicology, 52, 321-336. doi:10.1146/ annurev-pharmtox-010611-134625

Volkow, N. D., Wang, G.-J., Telang, F., Fowler, J. S., Logan, J., Childress, A.-R., \& Wong, C. (2006). Cocaine cues and dopamine in dorsal striatum: Mechanism of craving in cocaine addiction. Journal of Neuroscience, 26, 6583-6588. doi:10.1523/JNEUROSCI.1544-06. 2006

Vollstädt-Klein, S., Kobiella, A., Bühler, M., Graf, C., Fehr, C., Mann, K., \& Smolka, M. N. (2011). Severity of dependence modulates 
smokers' neuronal cue reactivity and cigarette craving elicited by tobacco advertisement. Addiction Biology, 16, 166-175.

Vuilleumier, P. (2015). Affective and motivational control of vision. Current Opinion in Neurology, 28, 29-35. doi:10.1097/WCO. 0000000000000159

Wagner, D. D., Dal Cin, S., Sargent, J. D., Kelley, W. M., \& Heatherton, T. F. (2011). Spontaneous action representation in smokers when watching movie characters smoke. Journal of Neuroscience, 31, 894-898. doi:10.1523/JNEUROSCI.5174-10.2011

Wanat, M. J., Willuhn, I., Clark, J. J., \& Phillips, P. E. (2009). Phasic dopamine release in appetitive behaviors and drug addiction. Current Drug Abuse Reviews, 2, 195-213.

Whalen, P. J., Kagan, J., Cook, R. G., Davis, F. C., Kim, H., Polis, S., \& Johnstone, T. (2004). Human amygdala responsivity to masked fearful eye whites. Science, 306, 2061. doi:10.1126/science.1103617

Wicker, B., Keysers, C., Plailly, J., Royet, J., Gallese, V., \& Rizzolatti, G. (2003). Both of us disgusted in my insula: The common neural basis of seeing and feeling disgust. Neuron, 40, 655-664.

Wilson, S. J., Sayette, M. A., \& Fiez, J. A. (2004). Prefrontal responses to drug cues: A neurocognitive analysis. Nature Neuroscience, 7, 211214.

World Health Organization. (2002). The world health report 2002. Geneva: Author.
World Health Organization. (2012). Management of substance abuse: The global burden [Website]. Available at www.who.int/ substance_abuse/facts/global_burden/en/

Yalachkov, Y., Kaiser, J., Görres, A., Seehaus, A., \& Naumer, M. J. (2012). Smoking experience modulates the cortical integration of vision and haptics. NeuroImage, 59, 547-555. doi:10.1016/j. neuroimage.2011.07.041

Yalachkov, Y., Kaiser, J., Görres, A., Seehaus, A., \& Naumer, M. J. (2013). Sensory modality of smoking cues modulates neural cue reactivity. Psychopharmacology, 225, 461-471. doi:10.1007/ s00213-012-2830-x

Yalachkov, Y., Kaiser, J., \& Naumer, M. J. (2009). Brain regions related to tool use and action knowledge reflect nicotine dependence. Journal of Neuroscience, 29, 4922-4929. doi:10.1523/ JNEUROSCI.4891-08.2009

Yalachkov, Y., Kaiser, J., \& Naumer, M. J. (2010). Sensory and motor aspects of addiction. Behavioural Brain Research, 207, 215-222.

Zoia, S., Blason, L., D’Ottavio, G., Bulgheroni, M., Pezzetta, E., Scabar, A., \& Castiello, U. (2007). Evidence of early development of action planning in the human foetus: A kinematic study. Experimental Brain Research, 176, 217-226.

Zwaigenbaum, L., Bryson, S., \& Garon, N. (2013). Early identification of autism spectrum disorders. Behavioural Brain Research, 251, 133 146. doi:10.1016/j.bbr.2013.04.004 